\title{
Magnitude determination of deep-focus earthquakes in and around Japan with regional velocity-amplitude data
}

\author{
Akio Katsumata \\ Meteorological College, JMA, 7-4-81 Asahi-cho, Kashiwa, Chiba 277-0852, Japan \\ (Received September 7, 1999; Revised January 23, 2001; Accepted March 2, 2001)
}

\begin{abstract}
This paper proposes a new method to determine earthquake magnitude for small deep-focus earthquakes by using velocity-amplitude data. For deep-focus earthquakes, body-wave magnitude has been widely used, but it is difficult to directly apply the conventional methods to the data from short-period seismometers of regional networks. In the proposed method, moment magnitude is used to obtain the attenuation function for epicentral distance and focal depth, where the influence of inhomogeneous $Q$ structure is incorporated. This effect is further reduced by introducing a correction term that is a function of distance from the trench axis to an observation station and focal depth. The attenuation function and correction term were estimated for the velocity amplitude data obtained by the network of the Japan Meteorological Agency. The velocity-amplitude magnitude we propose is in satisfactory agreement with the moment magnitude, and provides stable magnitude values for small earthquakes of deep to shallow focal depths seamlessly.
\end{abstract}

\section{Introduction}

Short-period velocity seismometers with the natural period of $T_{0} \simeq 1 \mathrm{~s}$ have been used to observe small earthquakes. Various formulas have been proposed in the literature to determine earthquake magnitude with amplitude data obtained from short-period velocity seismometers.

Kanbayashi and Ichikawa (1977) and Takeuchi (1983) proposed formulas for computing magnitude of small shallow earthquakes (depth $\leq 60 \mathrm{~km}$ ) for the data measured from short-period velocity seismometers deployed by the Japan Meteorological Agency (JMA). The formulas of Kanbayashi and Ichikawa (1977) and Takeuchi (1983) are

$$
\begin{aligned}
& M=\log _{10} A_{V}+1.64 \log _{10} \Delta+0.22, \\
& M=\log _{10} A_{V}+1.64 \log _{10} \Delta+0.44,
\end{aligned}
$$

respectively, where $A_{V}$ is half the maximum peak-to-peak velocity amplitude of the whole trace of the seismic record on the vertical component in milli-kine $\left(10^{-3} \mathrm{~cm} / \mathrm{s}\right)$ and $\Delta$ is epicentral distance $(\mathrm{km})$. Equations (1) and (2) are used for the data obtained from seismometers installed on the ground surface and in boreholes, respectively. These formulas were devised to provide earthquake magnitudes of small earthquakes in consistent with the magnitude determined with Tsuboi's (1954) formula. Tsuboi's formula is used by JMA to determine magnitude from displacement amplitudes obtained from seismometers of 5-6 s characteristic periods. An earthquake magnitude greater than or equal to 5.5 reported by JMA is displacement-amplitude magnitude based on the Tsuboi's formula; a magnitude less than 5.5 is the average

Copy right $(\mathcal{C}$ The Society of Geomagnetism and Earth, Planetary and Space Sciences (SGEPSS); The Seismological Society of Japan; The Volcanological Society of Japan; The Geodetic Society of Japan; The Japanese Society for Planetary Sciences. of displacement and velocity-amplitude magnitudes determined with Eqs. (1) and (2).

JMA seismic catalog is often referred to for investigating seismicity in and around Japan. But it was pointed out that Eqs. (1) and (2) were not properly connected with the Tsuboi's magnitude, and in particular that the value of 1.0 was not proper as the coefficient of $\log _{10} A_{V}$ (e.g., Kakishita et al., 1992). Figure 1 shows magnitude-frequency relationship of JMA magnitude, $M_{J M A}$, for the period from April, 1995 to September, 1997 (open circle). For $M_{J M A}$, a clear bend is seen around magnitude 5 in the figure. It is generally considered that the bend is due to the improper value of the coefficient of $\log _{10} A_{V}$.

Watanabe (1971) proposed an equation to relate earthquake magnitude to velocity amplitude obtained from shortperiod seismometers of regional networks:

$$
\begin{array}{r}
\log _{10} A_{V}=0.85 M-1.73 \log _{10} r-2.50, \\
(r \leq 200 \mathrm{~km})
\end{array}
$$

where $A_{V}$ is the maximum vertical velocity amplitude in kine (cm/s), $M$ is the magnitude defined by Tsuboi (1954), and $r$ is hypocentral distance $(\mathrm{km})$. Kakishita et al. (1992) showed data which supported the result of Watanabe (1971).

For the coefficient of $M$ that relates the maximum vertical velocity to the Tsuboi's magnitude, 0.85 in Eq. (3), Yoshioka and Iio (1988) used a value of 0.78. Relationship between magnitude and strong ground velocity has been examined to estimate peak ground motion from magnitude for disastrous earthquakes. Molas and Yamazaki (1995) obtained a coefficient of 0.628 to express the relationship between peak ground velocity and the Tsuboi's magnitude. Coefficients of 0.489 and 0.51 were used for the relationship between moment magnitude and peak ground velocity by Joyner and Boore (1981) and Campbell (1997), respectively. These re- 
ports indicate that the coefficient of $\log _{10} A_{V}$ in Eqs. (1) and (2) should be greater than 1.0.

For deep-focus earthquakes, body-wave magnitude, $m_{b}$, is estimated from global data, and some calibration functions were also proposed to determine body wave magnitudes from data obtained at local or regional distances (e.g., Duda, 1971; Veith and Clawson, 1972; Solov'yeva, 1978). However, those methods are based on the displacement amplitude, and it may not be suitable to apply them to the current JMA network.

We aim to give a means of determining earthquake magnitude of a deep-focus event by using data measured from short-period velocity instruments of regional distance. The new method of magnitude determination developed in this

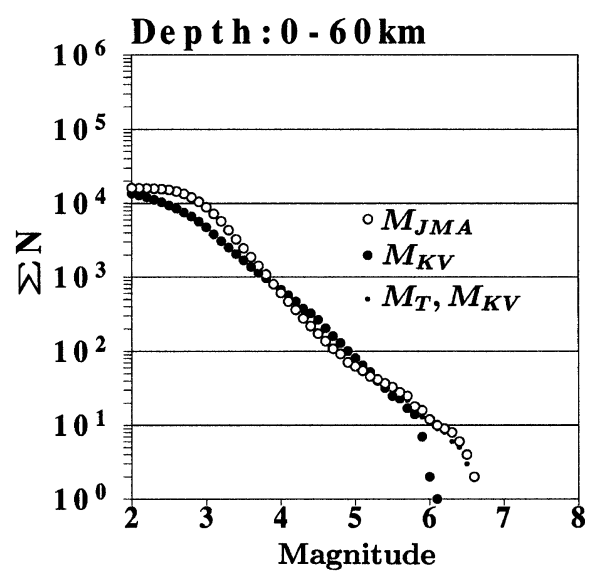

Fig. 1. Magnitude-frequency relationship of JMA magnitude scale, $M_{J M A}$, from April, 1995 to September, 1997 in the areas within $200 \mathrm{~km}$ from coastlines of the Japanese islands (open circle). The vertical axis shows the number of earthquakes larger than the magnitude on the horizontal axis. Magnitude-frequency relationship of the velocity-amplitude magnitude, $M_{K V}$, proposed in this paper (large solid circle) and a combination of the displacement-amplitude magnitude (Tsuboi, 1954), $M_{T}$, and $M_{K V}$ (small solid circle) are also shown. paper is scaled to the moment magnitude, $M_{w}$. We assume that the relationship among $M_{w}$, half the maximum peakto-peak velocity amplitude of vertical component, $A_{V}(\mathrm{~m} / \mathrm{s})$, epicentral distance, $\Delta$, and focal depth, $H$, is approximated as

$$
M_{w}=\alpha_{V} \log _{10} A_{V}+\beta_{V}(\Delta, H),
$$

where $\beta_{V}(\Delta, H)$ is an attenuation function of velocity amplitude, and $\alpha_{V}$ is a constant scaling factor which relates magnitude to the logarithm of velocity amplitude.

\section{Seismic Moment Estimation of Small Deep- Focus Earthquakes}

For the earthquakes occurring in and around the Japanese islands, some seismic moment catalogs are available (e.g.,

Table 1. Velocity structure model used to calculate synthetic records for estimating seismic moments.

\begin{tabular}{|c|c|c|c|}
\hline $\begin{array}{c}V_{P} \\
(\mathrm{~km} / \mathrm{s})\end{array}$ & $\begin{array}{c}V_{S} \\
(\mathrm{~km} / \mathrm{s})\end{array}$ & $\begin{array}{l}\text { Density } \\
\left(\mathrm{g} / \mathrm{cm}^{3}\right)\end{array}$ & $\begin{array}{c}\text { Depth of Layer Top } \\
(\mathrm{km})\end{array}$ \\
\hline 4.20 & 2.42 & 2.40 & 0.0 \\
\hline 5.30 & 3.06 & 2.60 & 2.4 \\
\hline 6.10 & 3.52 & 2.70 & 4.0 \\
\hline 6.70 & 3.97 & 3.00 & 14.6 \\
\hline 7.90 & 4.36 & 3.20 & 31.0 \\
\hline 7.98 & 4.56 & 3.37 & 115.0 \\
\hline 8.52 & 4.59 & 3.43 & 220.0 \\
\hline 8.87 & 4.65 & 3.49 & 300.0 \\
\hline 9.09 & 4.87 & 3.72 & 400.0 \\
\hline 9.34 & 5.01 & 3.78 & 450.0 \\
\hline 9.60 & 5.16 & 3.85 & 500.0 \\
\hline 10.11 & 5.45 & 3.98 & 600.0 \\
\hline 10.73 & 5.91 & 4.30 & 670.0 \\
\hline
\end{tabular}

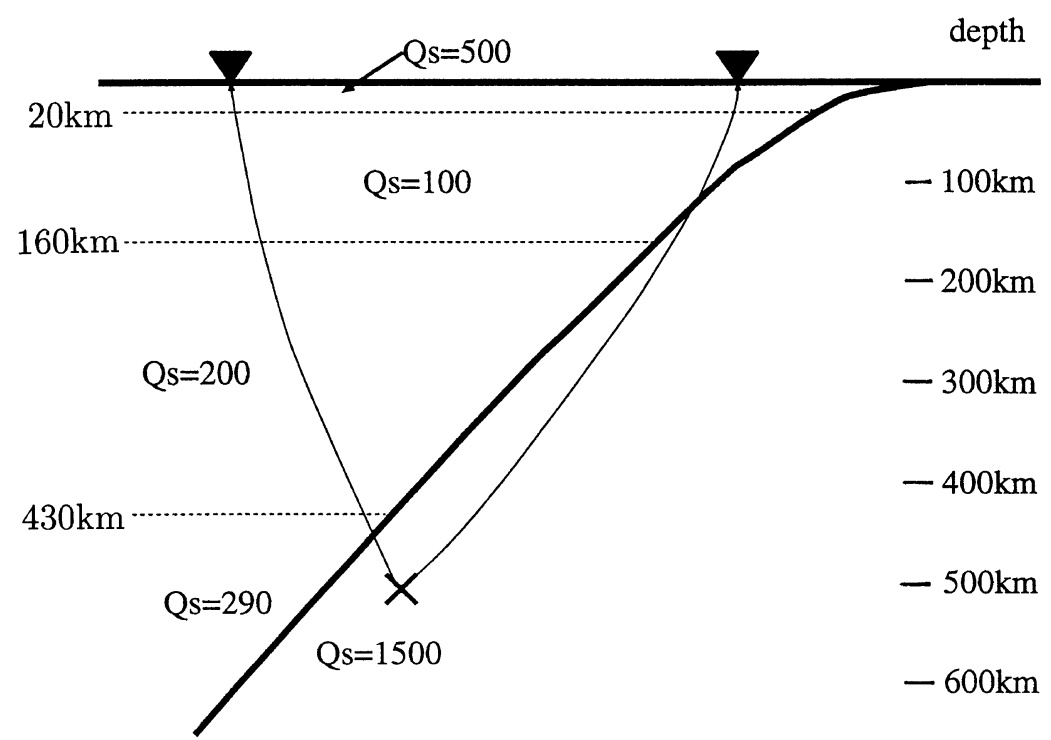

Fig. 2. Assumed $Q_{S}$ structure for calculating synthetic records. 


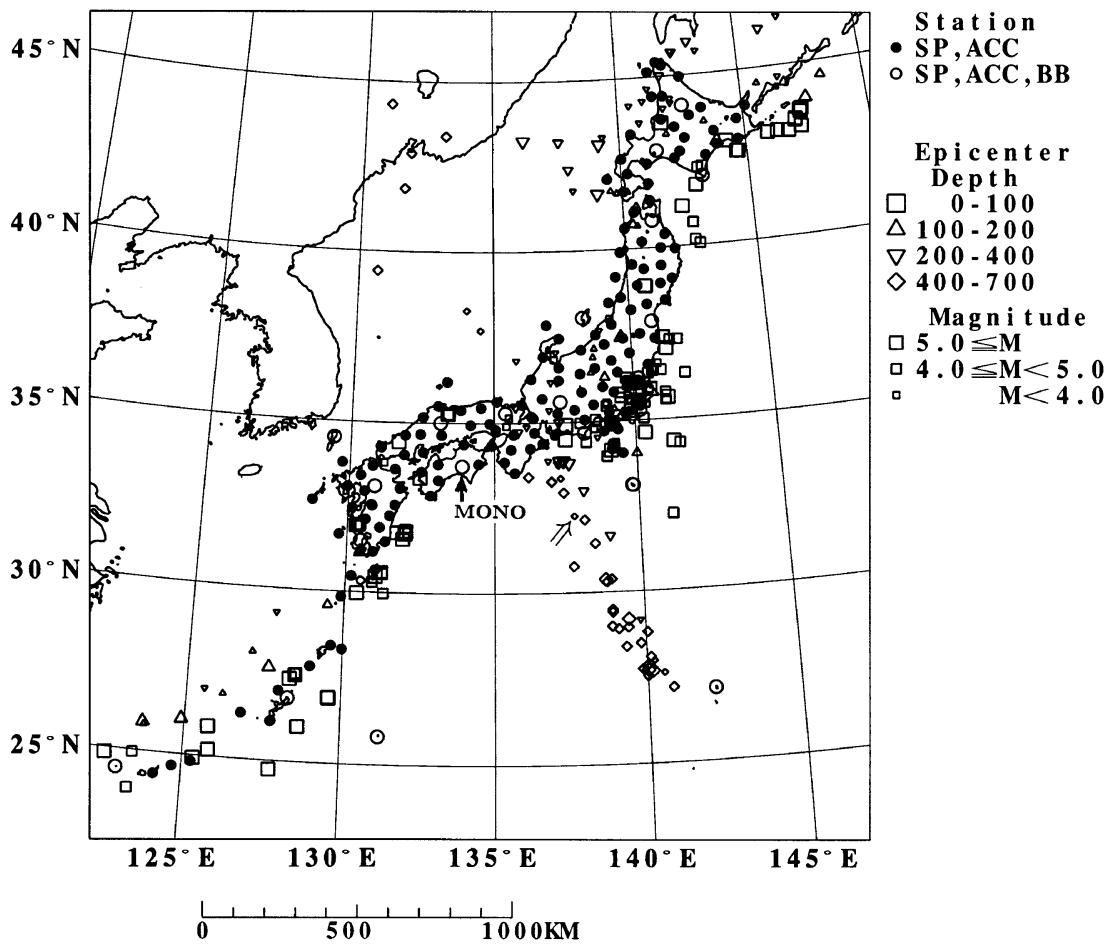

Fig. 3. Stations used to estimate seismic moments and epicenters of earthquakes for which seismic moments were estimated. All the stations are equipped with a short-period moving-coil seismometer (SP) and a feedback-type accelerometer (ACC). A broadband seismometer (BB) is also available at the stations of open circles. Locations of the epicenter (arrow) and the station (MONO) for the records in Fig. 14 are also indicated.

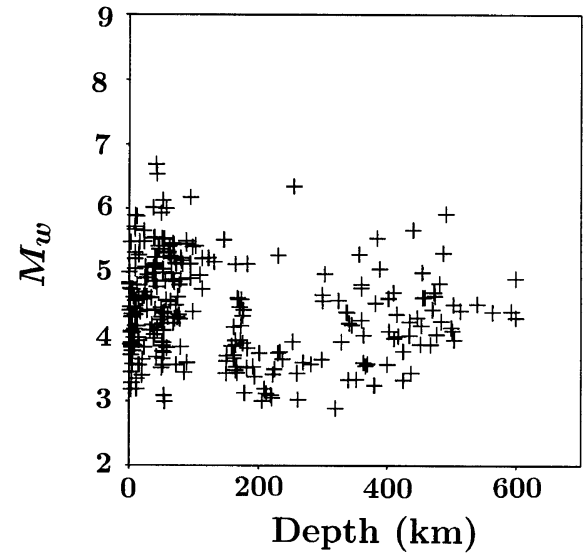

Fig. 4. Magnitude-depth distribution of estimated seismic moments in this study.

Dziewonski et al., 1981; Kikuchi and Ishida, 1993; Kawakatsu, 1995; Fukuyama et al., 1998). But, none of these catalogs covers the earthquakes of magnitude less than 5 and depth beneath $100 \mathrm{~km}$ with enough number of solutions. Therefor, we estimate seismic moments of small deepfocus earthquakes in this study to make a base for estimating $\beta_{V}(\Delta, H)$.

Anelastic attenuation is very important to estimate seismic moment of a deep-focus earthquake. Figure 2 shows the assumed $Q_{S}$ model for calculating synthetic records. $Q_{S}$ of crust is assumed to be 500, referring to the results of Umino and Hasegawa (1984) and Hashida (1989). $Q_{S}$ of
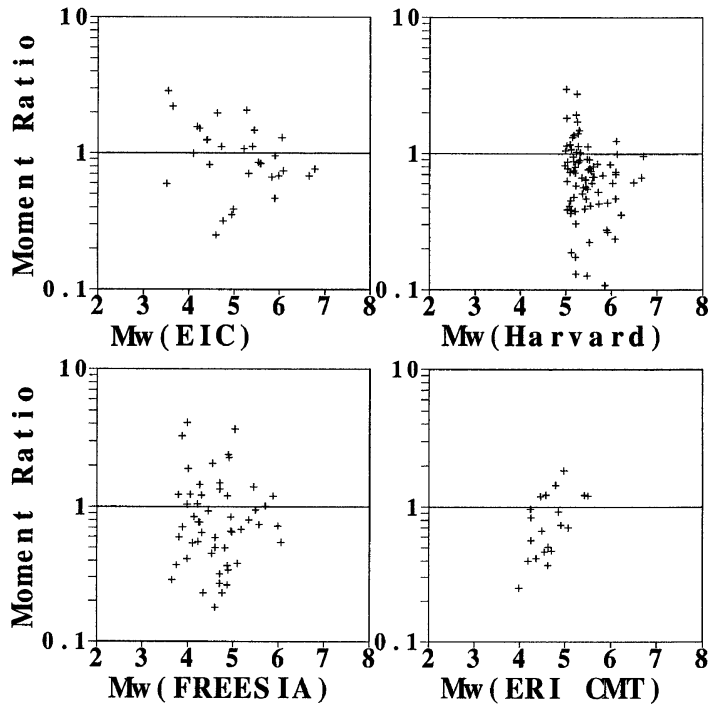

Fig. 5. Comparison of estimated scalar moments with those of various seismic moment catalogs. The horizontal axis shows moment magnitude. The vertical axis shows the ratio of the scalar moment in this study to that of various moment catalogs. Solutions estimated with the methods by Kikuchi and Ishida (1993), Dziewonski et al. (1981), Fukuyama et al. (1998), and Kawakatsu (1995) are referred to as "EIC", "Harvard", "FREESIA", and "ERI CMT", which represent names of groups or projects publishing the solutions, respectively.

subducting plates is assumed to be 1500 , referring to Umino and Hasegawa (1984) and Bowman (1988). The research by Flanagan and Wiens (1994) was referred to for assuming upper mantle $Q_{S}$ structure above subducting plates. The $Q_{S}$ 
values in Fig. 2 were assumed 1.7 times as large as those of the model by Flanagan and Wiens (1994), taking the frequency dependence of $Q_{S}$ reported by Choy and Cormier (1986) into consideration. $Q_{P}$ was assumed to be $\frac{9}{4} Q_{S}$ (Anderson et al., 1965).

Synthetic records for seismic moment estimation were calculated with the method of Takeo (1985) for the layered velocity structure shown in Table 1 . In the method, $Q$ value in a layer is constant. To reflect inhomogeneous $Q$ structure in Fig. 2 in the layered structure, $Q$ value of a layer for synthetic calculation was given as an average along a ray path in the model of Fig. 2.
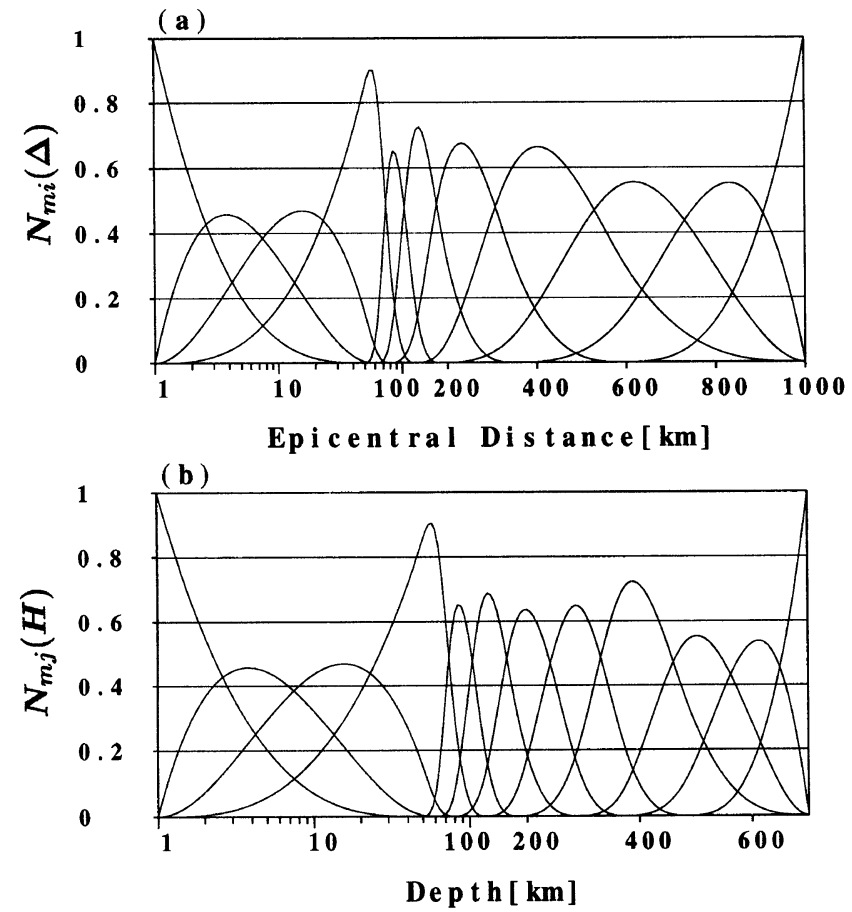

Fig. 6. B-spline functions used in this study to express an attenuation function for velocity amplitude, $\beta_{V}(\Delta, H)$ (Eq. (4)). The upper graph (a) shows the spline functions for epicentral distance, and the lower graph (b) shows those for focal depth. A combination of logarithmic and linear scales was adopted to permit a sufficient number of spline functions to be depicted over the broad range of hypocentral distances.

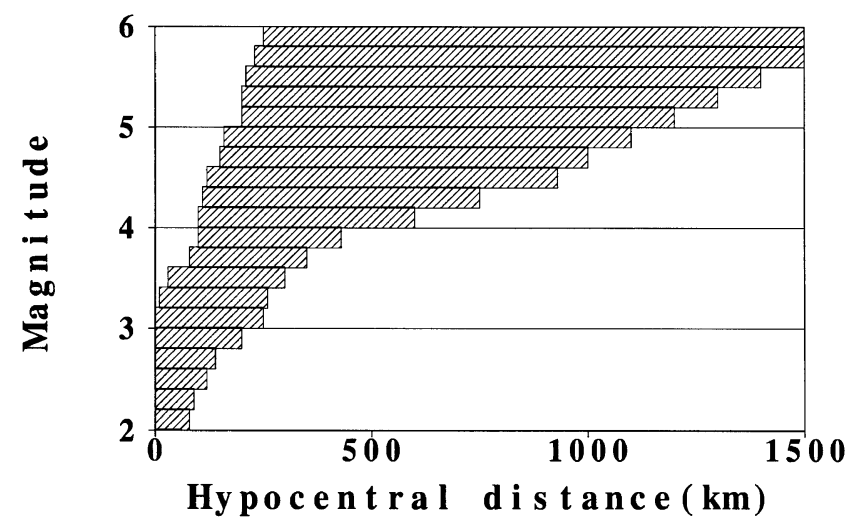

Fig. 7. Data windows used to avoid average shift due to the limitation of observed values in the estimation of the attenuation function.
Body waves records obtained from the JMA network (Japan Meteorological Agency, 1997) for the period from April, 1995 to September, 1997 were used to estimate seismic moments. The station map is shown in Fig. 3. All the stations are equipped with a short-period moving-coil seismometer and a feedback-type accelerometer, and a broadband seismometer (STS-2) is also available at the stations of open circles. Displacement records obtained by numerical integration of velocity and acceleration records were compared with synthetic ones by using a tool developed by Katsumata (2000). The frequency response of short-period instruments was compensated before the integration. Frequency bands for seismic moment estimation were changed depending on body-wave pulse widths of analyzed earthquakes within a range of 0.05-2.0 Hz. A manual source-parameter search was used in the estimation as well as the inversion method. For some earthquakes with focal mechanisms known from $P$-phase initial motions, only scalar moments were esti-

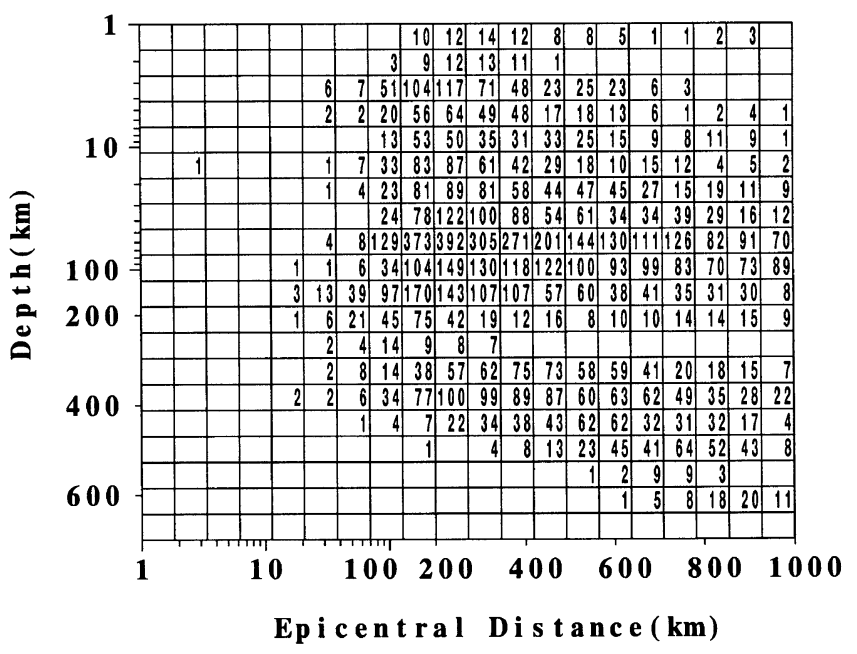

Fig. 8. Data distribution used for the estimation of the attenuation function. Each number denotes the number of data points in each $0.26(\Delta) \times 0.21(H)$ grid of $y$ in Eq. (5).

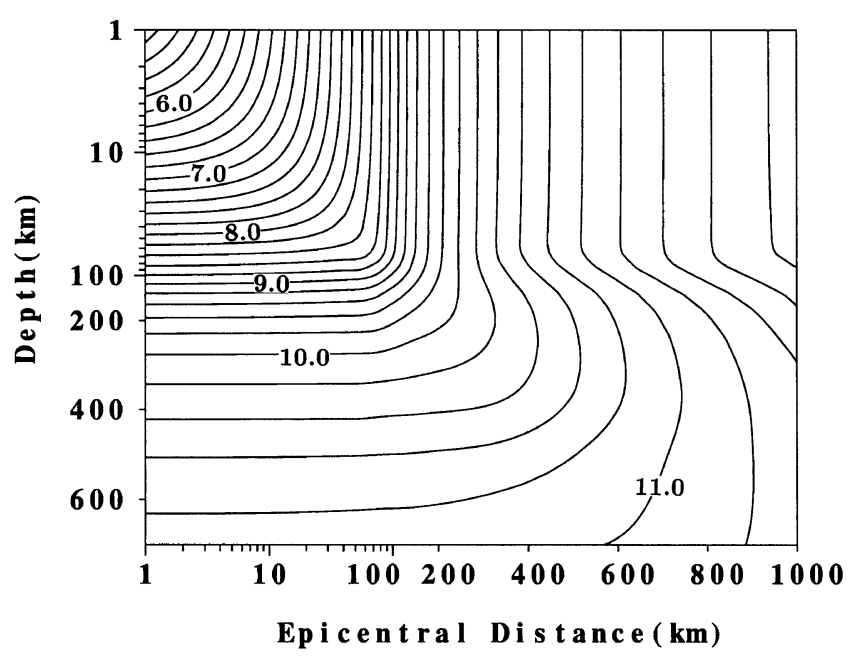

Fig. 9. The estimated attenuation function $\beta_{V}(\Delta, H)$ in Eq. (4). 

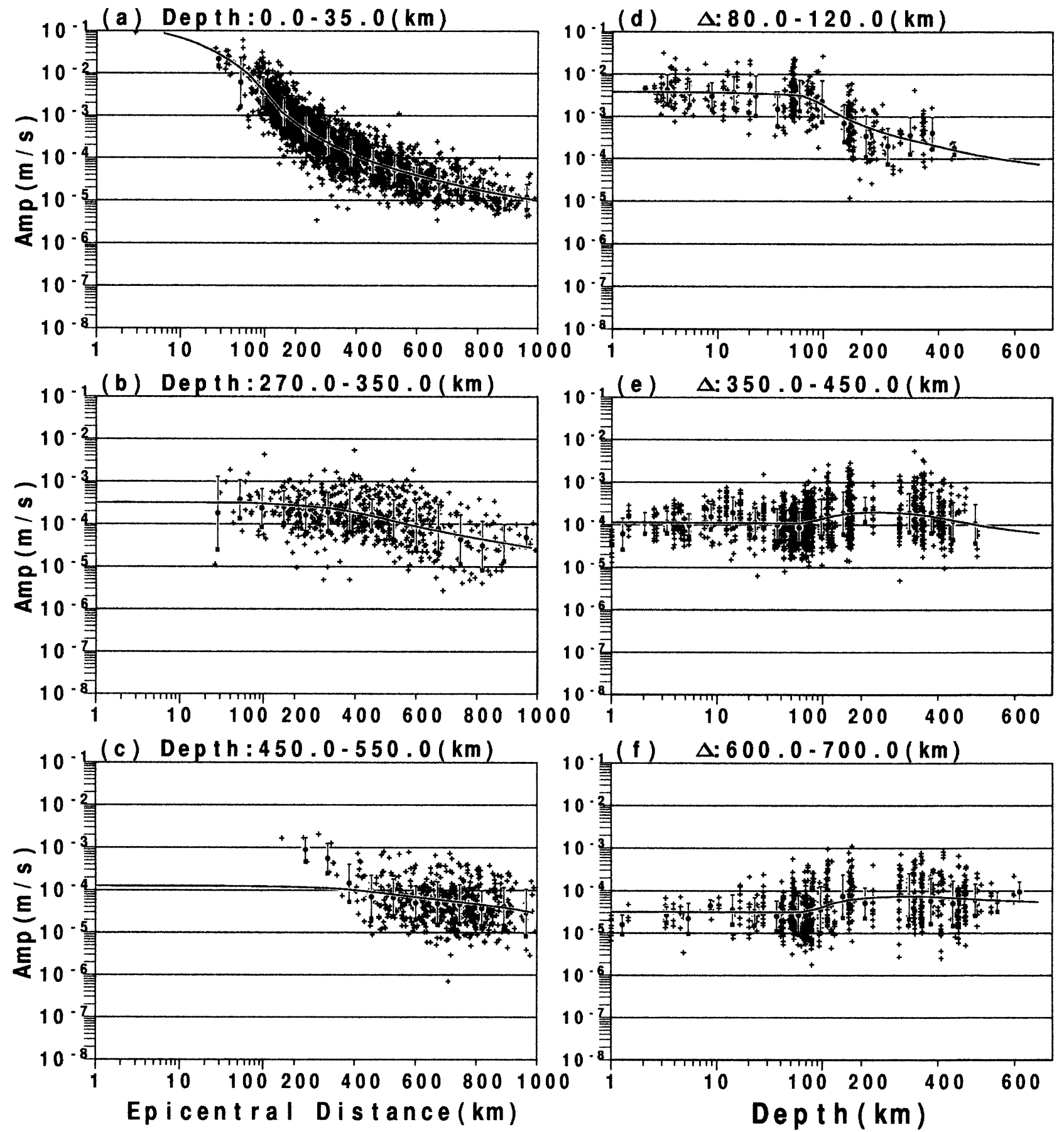

Fig. 10. The estimated attenuation function with data points. The vertical axis shows $\log _{10} A_{V}-\left(M_{w}-M_{s t d}\right) / \alpha_{V}$, where $M_{s t d}=5.0$. (a)-(c) show the relationships between amplitude and the epicentral distance, $\Delta$, and (d)-(f) show the relationships between amplitude and focal depth, $H$. A solid curve shows $\left\{M_{s t d}-\beta(\Delta, H)\right\} / \alpha_{V}$. The plotted curves of $\beta_{V}(\Delta, H)$ are computed for the central values of the $H$ or $\Delta$ ranges. The average and the standard deviation of each sectioned range are shown with a solid circle and a bar, respectively.

mated. Data from $2 \sim 10$ stations with epicentral distance of $6 \sim 1,100 \mathrm{~km}$ were used for each event. Seismic moments of 290 earthquakes of $M_{w}=3.0 \sim 6.7$ and $H=0 \sim 599$ $\mathrm{km}$ were estimated. We plot $M_{w}$ thus obtained against focal depth in Fig. 4.

Estimated scalar moments are compared with those of various moment tensor catalogs in Fig. 5. Scalar moments of this study are smaller than those estimated with the methods by Dziewonski et al. (1981), Fukuyama et al. (1998), and
Kawakatsu (1995) by a factor of about 1.5, and do not differ very much from the solutions by Kikuchi and Ishida (1993) on average. The root mean square (RMS) of $\log _{10}\left(M_{0 i} / M_{0 j}\right)$ ranges from 0.25 to 0.36 , where $M_{0 i}$ is the scalar moment of the present study and $M_{0 j}$ is that of other moment catalogs. The RMS of $\log _{10}\left(M_{0 i} / M_{0 j}\right)$ ranges from 0.24 to 0.52 for all combinations of various moment catalogs. The scattering of $M_{0 i} / M_{0 j}$ for scalar moment in this study is not very large comparing with other moment catalogs. Thus, we assign the 
Table 2. Coefficients of spline functions $c_{i j}$ for $\beta_{V}(\Delta, H)$.

\begin{tabular}{lllllllllllc}
\hline & \multicolumn{1}{c}{$c_{1 j}$} & \multicolumn{1}{c}{$c_{2 j}$} & \multicolumn{1}{c}{$c_{3 j}$} & \multicolumn{1}{c}{$c_{4 j}$} & \multicolumn{1}{c}{$c_{5 j}$} & \multicolumn{1}{c}{$c_{6 j}$} & \multicolumn{1}{c}{$c_{7 j}$} & \multicolumn{1}{c}{$c_{8 j}$} & \multicolumn{1}{c}{$c_{9 j}$} & $c_{10 j}$ & $c_{11 j}$ \\
\hline$c_{i 1}$ & 5.07 & 5.71 & 6.71 & 8.31 & 8.60 & 9.21 & 9.88 & 10.64 & 11.33 & 11.72 & 11.88 \\
$c_{i 2}$ & 5.73 & 5.78 & 6.78 & 8.31 & 8.60 & 9.21 & 9.88 & 10.64 & 11.33 & 11.72 & 11.88 \\
$c_{i 3}$ & 6.74 & 6.71 & 6.58 & 8.33 & 8.61 & 9.22 & 9.88 & 10.64 & 11.33 & 11.72 & 11.88 \\
$c_{i 4}$ & 8.33 & 8.33 & 8.36 & 8.47 & 8.72 & 9.25 & 9.89 & 10.67 & 11.32 & 11.73 & 11.86 \\
$c_{i 5}$ & 8.60 & 8.60 & 8.65 & 8.86 & 8.92 & 9.29 & 9.92 & 10.56 & 11.28 & 11.69 & 11.81 \\
$c_{i 6}$ & 9.12 & 9.12 & 9.13 & 9.22 & 9.35 & 9.55 & 9.93 & 10.39 & 11.04 & 11.47 & 11.67 \\
$c_{i 7}$ & 9.68 & 9.68 & 9.69 & 9.69 & 9.73 & 9.87 & 9.95 & 10.26 & 10.98 & 11.22 & 11.54 \\
$c_{i 8}$ & 10.06 & 10.06 & 10.06 & 10.07 & 10.07 & 10.09 & 10.15 & 10.25 & 10.92 & 11.20 & 11.39 \\
$c_{i 9}$ & 10.29 & 10.29 & 10.29 & 10.29 & 10.32 & 10.32 & 10.34 & 10.34 & 10.89 & 11.15 & 11.34 \\
$c_{i 10}$ & 10.67 & 10.67 & 10.67 & 10.68 & 10.68 & 10.68 & 10.71 & 10.73 & 11.00 & 11.11 & 11.34 \\
$c_{i 11}$ & 10.80 & 10.80 & 10.80 & 10.81 & 10.81 & 10.81 & 10.81 & 10.88 & 10.98 & 11.11 & 11.34 \\
$c_{i 12}$ & 10.88 & 10.88 & 10.88 & 10.89 & 10.91 & 10.91 & 10.94 & 10.98 & 10.99 & 11.14 & 11.35 \\
\hline
\end{tabular}

moment magnitude, $M_{w}$, by using our estimate of $M_{0}$ and Kanamori's (1977) relation:

$$
M_{w}=\left(\log _{10} M_{0}-9.1\right) / 1.5,
$$

where $M_{0}$ is the scalar moment $(\mathrm{Nm})$ of an earthquake.

\section{Estimation of the Velocity Amplitude Attenua- tion Function}

An attenuation function of velocity amplitude, $\beta_{V}(\Delta, H)$ (Eq. (4)), is derived based on the moment magnitude obtained in the previous section. The value of $\alpha_{V}$ (Eq. (4)) is fixed at $1 / 0.85$, following the result of Watanabe (1971) (see Eq. (3)). Validity of this assumption will be shown in a latter section.

We express $\beta_{V}(\Delta, H)$ with B-spline functions (Ichida and Yoshimoto, 1979) as

$$
\beta_{V}(\Delta, H)=\sum_{i=1}^{h-m} \sum_{j=1}^{k-m} c_{i j} N_{m i}(\Delta) N_{m j}(H)
$$

where $N_{m i}(\Delta)$ and $N_{m j}(H)$ are the spline functions, $m$ is the order of the functions, $h$ and $k$ are numbers of knots for epicentral distance and focal depth respectively, and $c_{i j}$ are constants, which are estimated by the least squares method with smoothing (see Katsumata, 1996).

A combination of logarithmic and linear scales (Fig. 6) is used as the variable of spline functions to put an enough number of spline functions to both close and far regions from a station. Logarithmic and linear scales are connected at a specific value of epicentral distance or focal depth so that the two scaling factors become identical at the connection point. The coordinate on the combined scale, $y$, is calculated as

$$
y= \begin{cases}\log _{10} x & \left(x \leq x_{c}\right) \\ \frac{x}{x_{c}} \log _{10} e+\log _{10} \frac{x_{c}}{e} & \left(x>x_{c}\right)\end{cases}
$$

where $x$ denotes epicentral distance or focal depth, $x_{c}$ is the coordinate of the connection point, and $e$ is the base of the natural logarithm. A value of $120 \mathrm{~km}$ is used as the connection point for both of epicentral distance and focal depth.

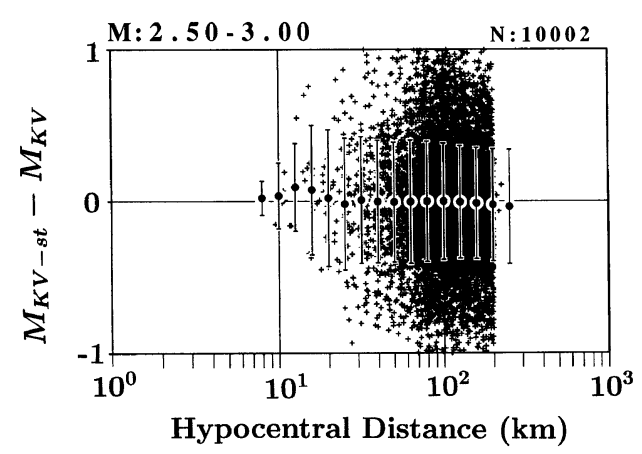

Fig. 11. Difference between earthquake magnitudes, $M_{K V}$, and station magnitudes, $M_{K V-s t}$, with hypocentral distance as the horizontal axis.

The connection point was selected to apply the logarithmic scale to a hypocentral distance range less than about $100 \mathrm{~km}$ where the attenuation function varies rapidly, and to keep the ratio of the linear scale from becoming too large. We set the knots on the combined scale as

knot coordinates for epicentral distance $\xi$

$$
\begin{gathered}
\xi_{i}=0.0,0.0,0.0,0.0,1.7,1.8,1.9,2.1,2.3,2.9,3.8, \\
5.265,5.265,5.265,5.265 \\
(i=-3,-2, \ldots, 11),
\end{gathered}
$$

knot coordinates for focal depth $\eta$

$$
\begin{gathered}
\eta_{j}=0.0,0.0,0.0,0.0,1.7,1.8,1.9,2.1,2.3,2.7, \\
3.0,3.4,4.179,4.179,4.179,4.179 \\
(j=-3,-2, \ldots, 12) .
\end{gathered}
$$

The attenuation function $\beta_{V}(\Delta, H)$ is estimated based on Eq. (4). Velocity amplitudes observed by JMA from April, 1995 to September, 1997 with short-period instruments in Fig. 3 are used as $A_{V}\left(10^{-3} \mathrm{~cm} / \mathrm{s}\right)$. However, the ground noise limits minimum observed amplitude, and clipping of the $\mathrm{A} / \mathrm{D}$ converter limits upper computable magnitude. To avoid this systematic bias of data, the data used for estimating $\beta_{V}$ are 

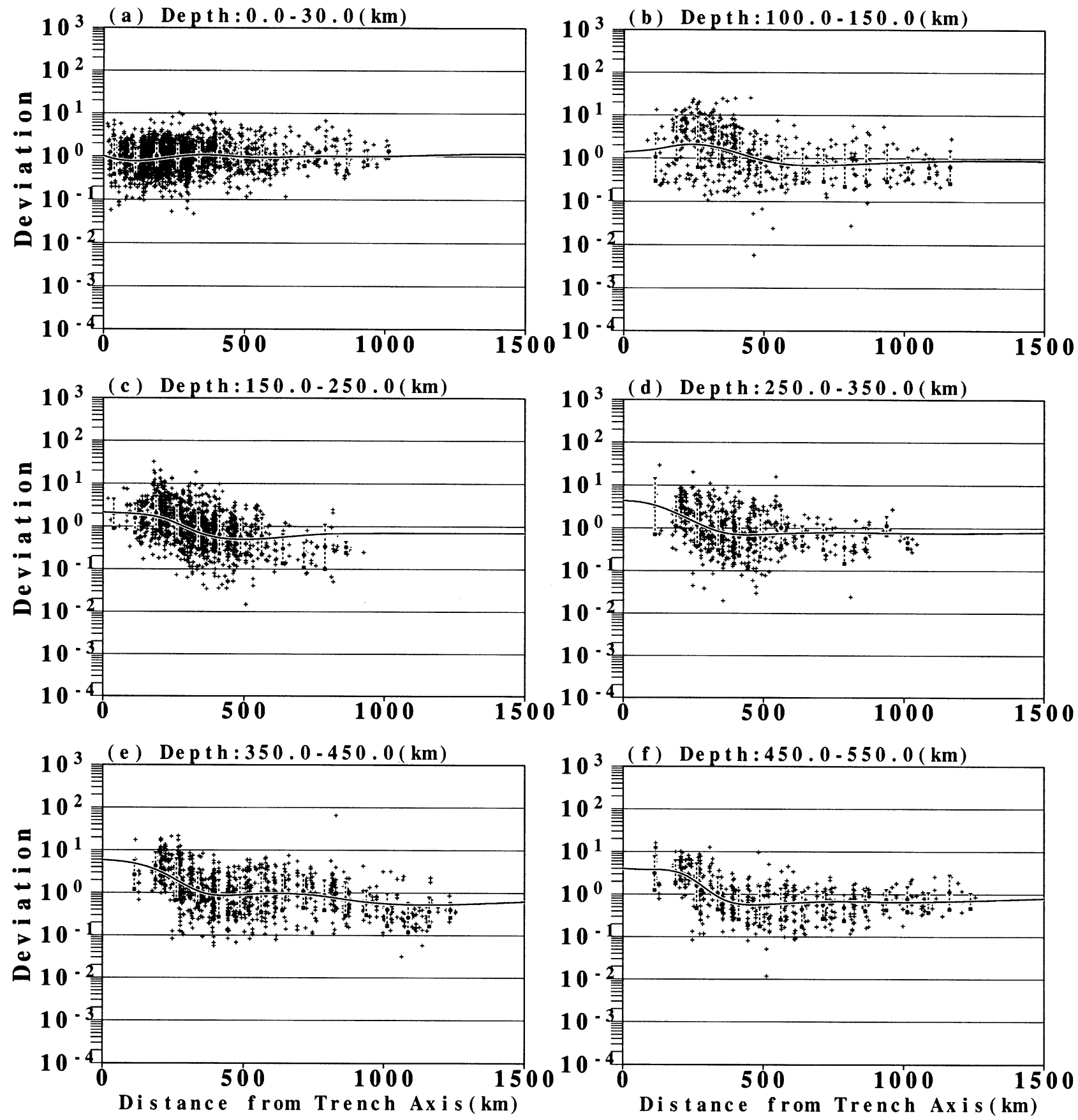

Fig. 12. Relationship between distance from the trench axis to the observation station and deviation of amplitude data from that expected from the estimated attenuation function, $\beta_{V}(\Delta, H)$. Solid curves show the value of $\gamma_{V}(L, H)$ in Eq. (6) for the centers of $H$ or $\Delta$ ranges.

selected by applying the magnitude-dependent windows of hypocentral distance as shown in Fig. 7.

We further limit the upper bound of $M_{w}$ since spectrum amplitude of seismic waves decay over the corner frequency (e.g., Aki, 1967). This causes saturation in magnitude for the short-period seismometers of our present concern. Kikuchi and Ishida (1993) showed an empirical relationship between seismic moment $M_{0}(\mathrm{Nm})$ and pulse width $\tau$ (s) of displacement $P$-wave for earthquakes deeper than $50 \mathrm{~km}$ and of $M_{w}=3 \sim 7$ as

$$
M_{0} / \tau^{3}=1.0 \times 10^{17}
$$

According to this relationship, moment magnitude of an earthquake with $1 \mathrm{~s}$ pulse width is $M_{w}=5.3$, and for $0.5 \mathrm{~s}$ pulse width, $M_{w}=4.7$. For earthquakes deeper than $50 \mathrm{~km}$, data of $M_{w} \leq 5.3$ are used in the estimation of $\beta_{V}(\Delta, H)$. Since earthquakes in the crust have longer pulse width versus earthquakes of similar sizes in the mantle, the upper limit of $M_{w}$ for shallow earthquakes $(H \leq 50 \mathrm{~km})$ is set at 4.7 . Although the corner frequency of $1 \mathrm{~Hz}$ corresponds to about $0.5 \mathrm{~s}$ duration for a triangle-shaped source time function, no clear saturation is seen in Fig. 1 up to about 5.8 magnitude units in velocity-amplitude magnitude. The assumed uppermost magnitude limits is enough to exclude attenuated data 
Table 3. Coefficients of spline functions $c_{i j}$ for $\gamma_{V}(L, H)$.

\begin{tabular}{rrrrrrrrrrr}
\hline & \multicolumn{1}{c}{$c_{1 j}$} & \multicolumn{1}{c}{$c_{2 j}$} & \multicolumn{1}{c}{$c_{3 j}$} & \multicolumn{1}{c}{$c_{4 j}$} & \multicolumn{1}{c}{$c_{5 j}$} & \multicolumn{1}{c}{$c_{6 j}$} & \multicolumn{1}{c}{$c_{7 j}$} & \multicolumn{1}{c}{$c_{8 j}$} & \multicolumn{1}{c}{$c_{9 j}$} & \multicolumn{1}{c}{$c_{10 j}$} \\
\hline$c_{i 1}$ & 0.00 & -0.05 & 0.07 & -0.15 & 0.04 & -0.28 & 0.36 & 0.12 & -0.09 & -0.09 \\
$c_{i 2}$ & -0.02 & 0.25 & 0.28 & 0.25 & -0.25 & 0.49 & -0.47 & -0.06 & -0.12 & -0.06 \\
$c_{i 3}$ & -0.04 & -0.05 & 0.21 & 0.12 & 0.14 & 0.00 & 0.12 & -0.06 & -0.12 & -0.06 \\
$c_{i 4}$ & -0.04 & -0.09 & -0.14 & -0.56 & -0.62 & 0.09 & 0.12 & -0.06 & -0.12 & -0.06 \\
$c_{i 5}$ & -0.41 & -0.38 & -0.35 & -0.24 & 0.32 & 0.53 & 0.38 & 0.35 & 0.35 & 0.35 \\
$c_{i 6}$ & -0.33 & -0.33 & -0.33 & -0.29 & 0.32 & 0.33 & 0.04 & 0.01 & 0.02 & 0.02 \\
$c_{i 7}$ & -0.96 & -0.95 & -0.86 & -0.24 & 0.19 & 0.09 & 0.18 & 0.18 & 0.16 & 0.14 \\
$c_{i 8}$ & -0.92 & -0.91 & -0.88 & -0.71 & 0.09 & -0.09 & -0.12 & 0.59 & 0.38 & 0.31 \\
$c_{i 9}$ & -0.59 & -0.55 & -0.56 & -0.71 & 0.51 & 0.65 & 0.45 & 0.08 & 0.06 & 0.02 \\
$c_{i 10}$ & -0.51 & -0.47 & -0.47 & -0.27 & 0.12 & -0.53 & -0.33 & -0.33 & -0.31 & -0.24 \\
$c_{i 11}$ & -0.49 & -0.45 & -0.33 & -0.26 & 0.20 & -0.04 & 0.02 & 0.00 & 0.00 & 0.00 \\
\hline
\end{tabular}

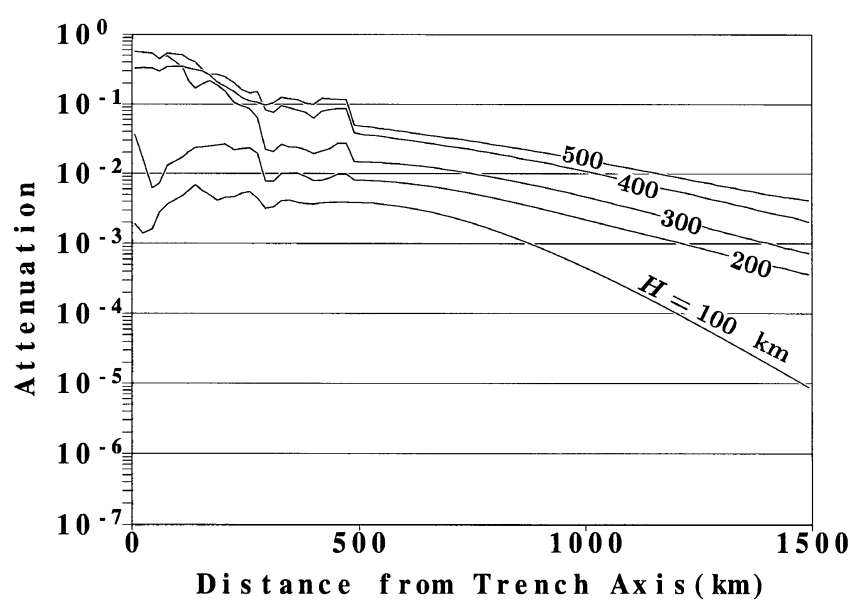

Fig. 13. Theoretical attenuation $\left(\exp \left(-\int \frac{\pi f}{Q_{S}} d t\right)\right)$ based on the model in Fig. 2. Latitudes of a hypocenter and stations are assumed to be $40^{\circ} \mathrm{N}$ and $35^{\circ} \mathrm{N}$, respectively.

due to the instrumental frequency response. Figure 8 shows the number of data points in each $0.26(\Delta) \times 0.21(H)$ grid of $y$ in Eq. (5). A total of 10,487 amplitudes from 196 earthquakes is used for obtaining $\beta_{V}(\Delta, H)$.

The estimated attenuation function is shown in Fig. 9 by contour curves, and values of $c_{i j}$ are listed in Table 2. Figure 10 illustrates the attenuation curves together with observation data for selected depth and epicentral distance ranges. The attenuation curves indicate satisfactory fit to the observation although the curves deviate from the average of data plots due to smoothing in some parts (e.g., Fig. 10(c)). In Figs. 10(e) and (f), the attenuation at shallow depths is larger than that at deeper depths. This is considered related to the effects of geometrical spreading. The standard deviation of all data is 0.66 , which is about double of that for displacement amplitude $(=0.34)$ obtained by Katsumata (1999).

The function is not a simple result of least squares analysis but a result with some additional corrections. Since the number of data within $100 \mathrm{~km}$ in hypocentral distance is not sufficient (Figs. 8 and 10), corrections were added to $c_{i j}$ for short hypocentral distances. Figure 11 shows the difference

\section{MONO D/U MONO N/S MONO E/W}

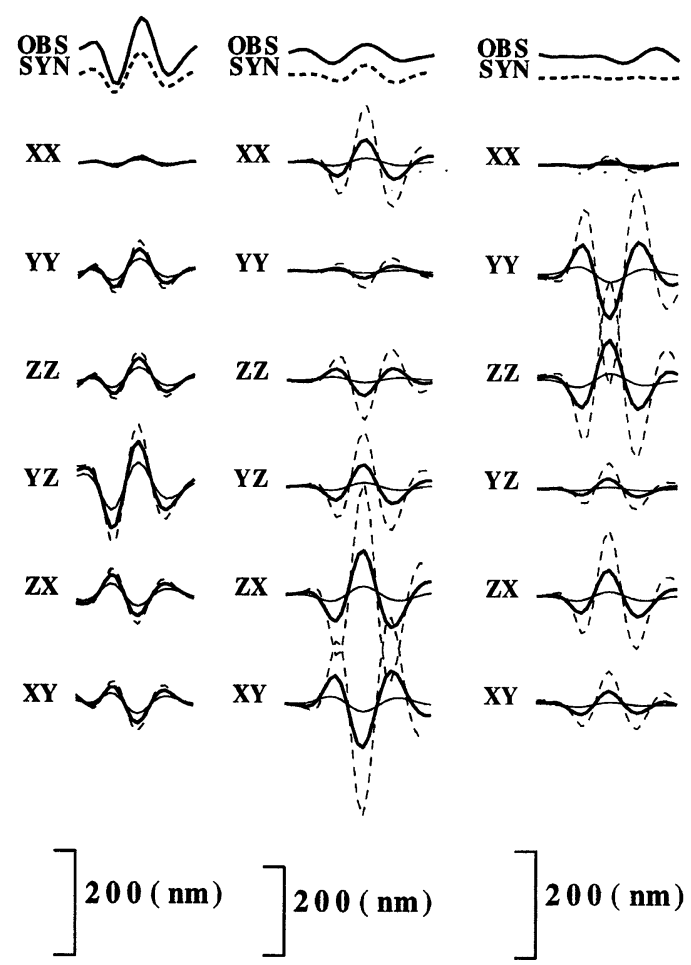

Fig. 14. Comparison of synthetic records for different $Q$ structures. The solid curve and the broken curve in the top panels of each component show a record segment observed at MONO of an earthquake which occurred on July 21, 1997 at a depth of $424 \mathrm{~km}$ (see Fig. 3) and fitted synthetic ones based on the $Q$ model in Fig. 2. Record segments of vertical components show $P$-phase, and records of horizontal components are those of $S$-phase. The curves in the lower panels of each component show synthetic records of each moment component. $X X$ and etc. denote components of a moment tensor. $X$ denotes N/S direction; $Y, \mathrm{E} / \mathrm{W}$ direction; and $Z, \mathrm{D} / \mathrm{U}$ direction. The synthetic of each moment component corresponds to $9.0 \times 10^{14} \mathrm{Nm}$. Bold solid curves, thin solid curves, and thin broken curves show synthetic records for the $Q$ structure shown in Fig. 2, for that with half $Q$ values of Fig. 2, and for that with double $Q$ values of Fig. 2, respectively. 

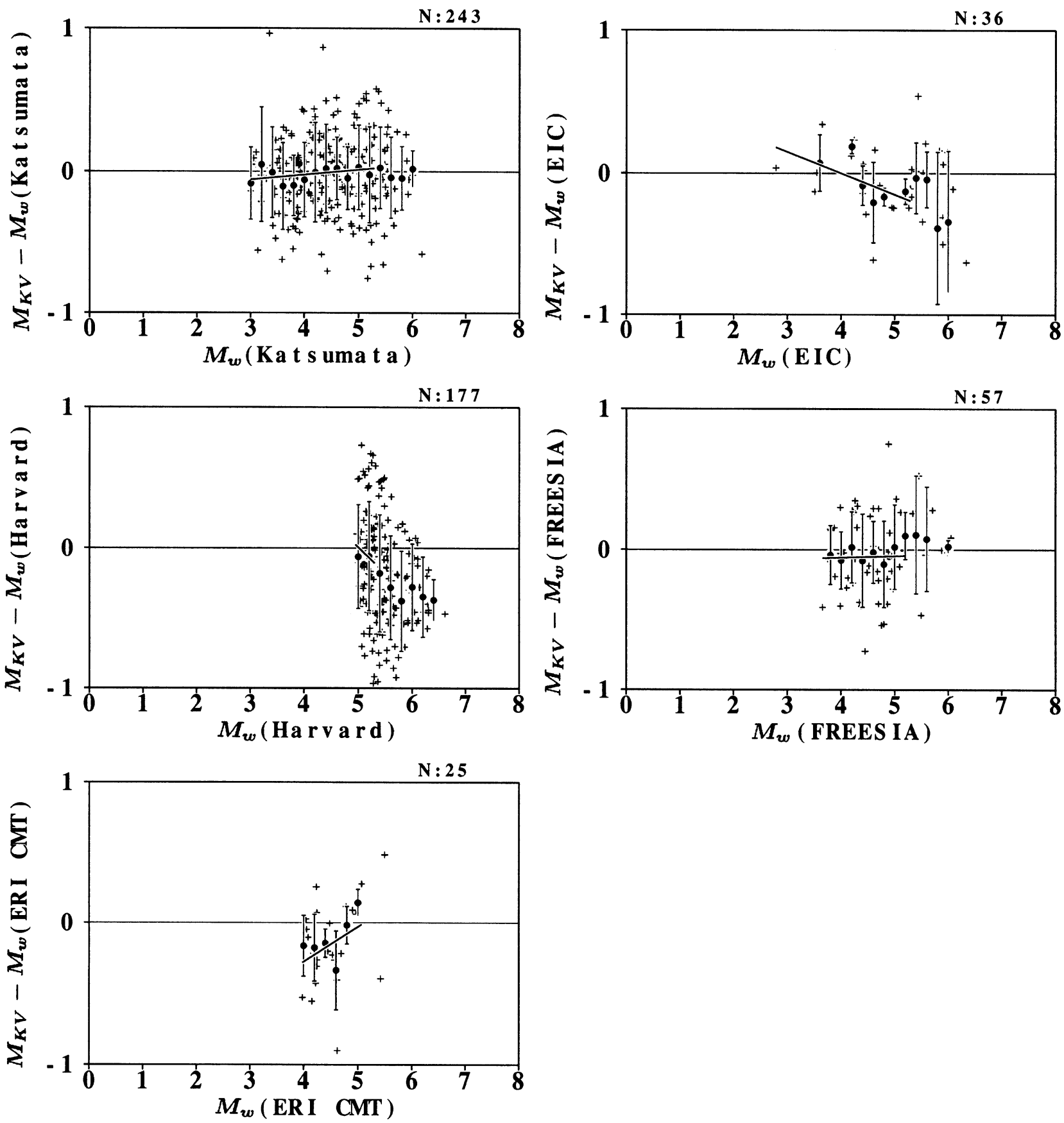

Fig. 15. Comparisons between moment magnitude of various catalogs and velocity-amplitude magnitude of this study, $M_{K} V$.

between earthquake magnitudes, $M_{K V}$, and station magnitudes, $M_{K V-s t}$, of earthquakes from April, 1995 to September, 1997 as a function of the hypocentral distance, where $M_{K V-s t}$ is calculated from the amplitude at a single station by using an equation:

$$
M_{K V-s t}=\alpha_{V} \log _{10} A_{V}+\beta_{V}(\Delta, H),
$$

and $M_{K V}$ is the average of $M_{K V-s t}$ over all the stations. Earthquakes without seismic moment estimates are included in Fig. 11. Earthquakes with magnitude range 2.5-3.0 are used to cover hypocentral distances between 10 and $200 \mathrm{~km}$. The function, $\beta_{V}(\Delta, H)$, was adjusted so that the averages of data plots would not deviate from the the line of $M_{K V-s t}-$
$M_{K V}=0$ in the hypocentral distance ranges shorter than $100 \mathrm{~km}$.

\section{Effect of Inhomogeneous $Q$ Structure on Esti- mating the Attenuation Function}

It is well known that subducting plates have relatively high $Q$ value comparing with the surrounding upper mantle. Therefore amplitudes should express dependence on distance from the trench axis due to the inhomogeneous $Q$ structure as was illustrated in Fig. 2. Figure 12 shows the relationship between distance measured along the earth surface from the trench axis to the observation station and deviation of amplitude data from that expected based on the estimated attenuation function $\beta_{V}(\Delta, H)$. For the case of deep events, 
(a)
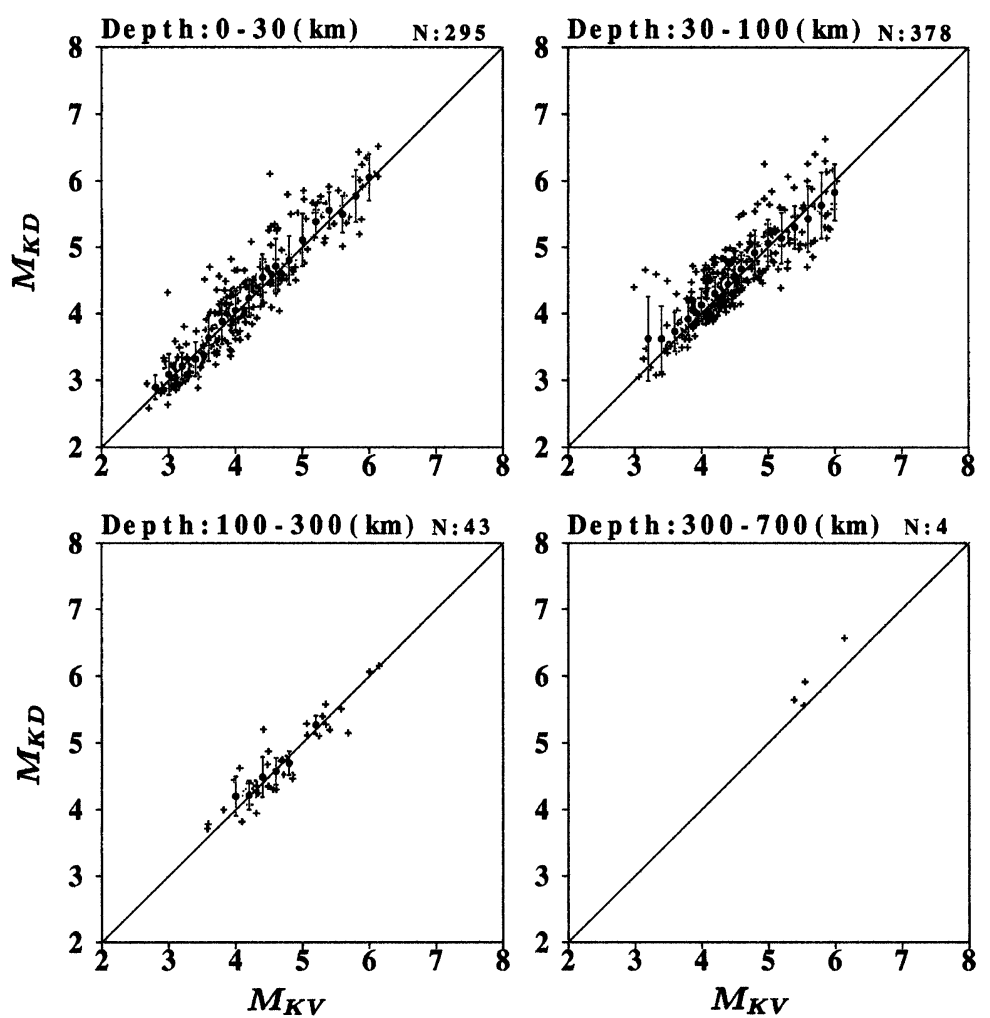

(b)
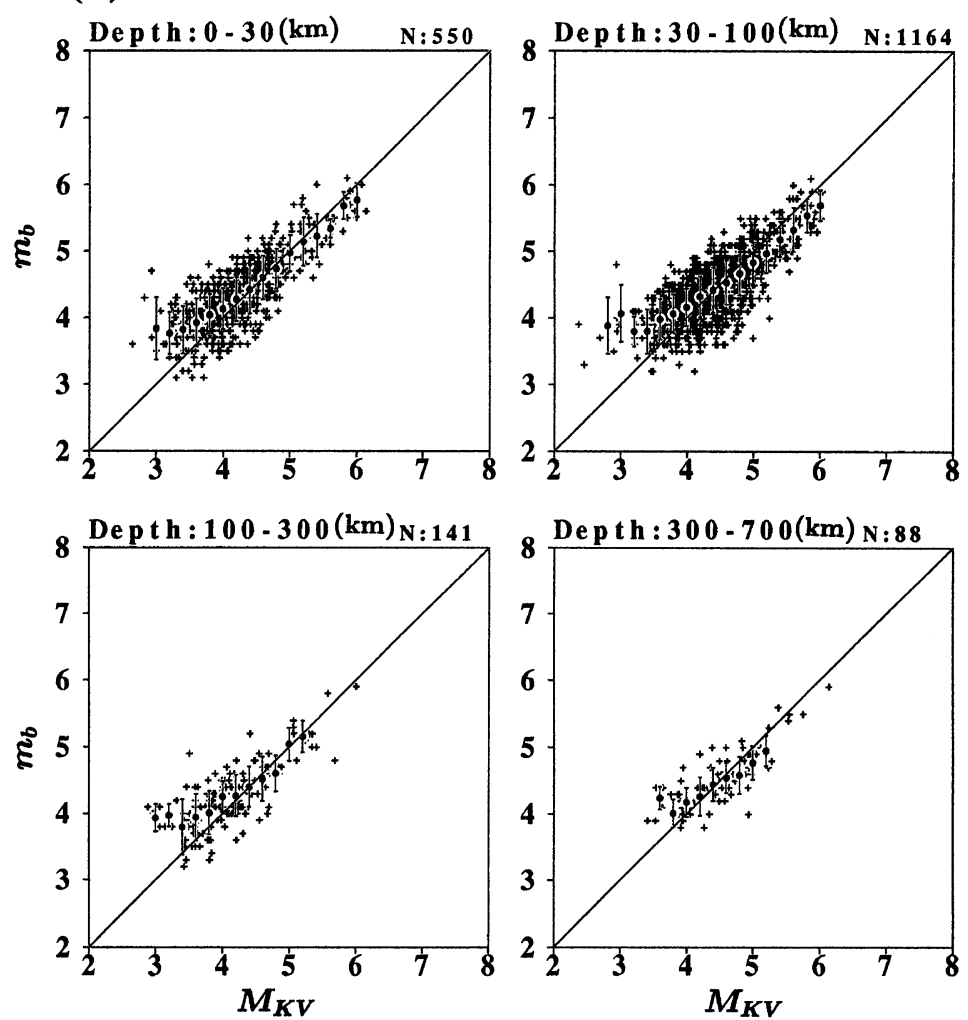

Fig. 16. Comparisons between the velocity-amplitude magnitude of this study, $M_{K V}$, and other kinds of magnitude (a) the displacement-amplitude magnitude of Katsumata (1999), $M_{K D}$, (b) the body-wave magnitude of the USGS, $m_{b}$, (c) the current JMA magnitude, $M_{J M A}$. 
(c)
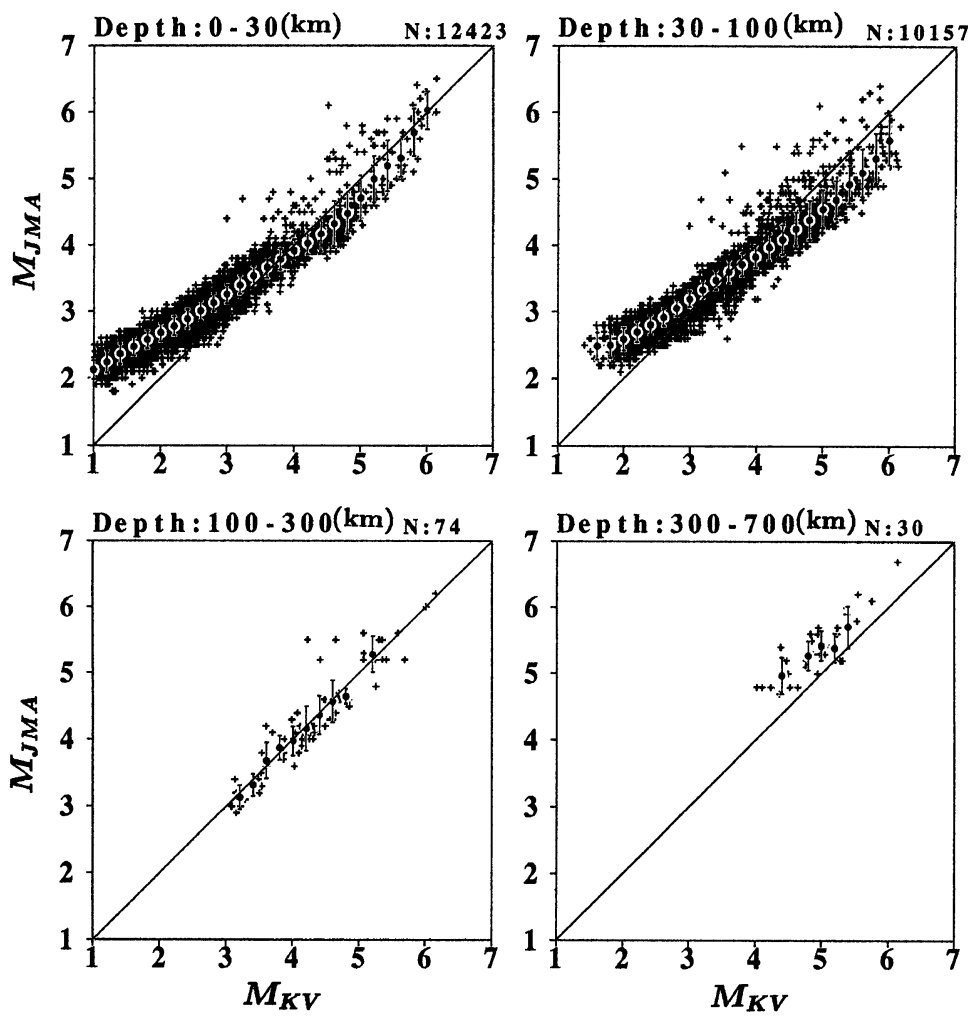

Fig. 16. (continued).

they occur in the Pacific plate or the Philippine Sea plate, and the distance is measured from the trench axis where the corresponding plate subducts. Dependence on distance from the trench axis is clearly seen in the figure. Average differences are not large for shallow earthquakes (Fig. 12(a)), and are notable for deep earthquakes (Figs. 12(c)-(f)). For deep earthquakes, the averaged deviations are over the expected levels in short distance ranges, and under those in long distance ranges (Figs. 12(b)-(f)). It is considered that the path length in high $Q$ slab is relatively short and the seismic waves attenuate more strongly for long distance ranges.

To correct the effect of the inhomogeneous $Q$ structure, we introduce $\gamma_{V}(L, H)$ to formulate the velocity attenuation:

$$
M_{w}=\alpha_{V} \log _{10} A_{V}+\beta_{V}(\Delta, H)+\gamma_{V}(L, H),
$$

where $\gamma_{V}(L, H)$ is a function of distance from the trench axis, $L$, and focal depth, $H$, which represents the effect of the inhomogeneous $Q$ structure. B-spline functions are used to express $\gamma_{V}(L, H)$. The coordinates of the knots are:

$$
\begin{gathered}
L_{i}=0,0,0,0,100,220,350,500,770,900, \\
1500,1500,1500,1500 \mathrm{~km} \\
(i=-3,-2, \ldots, 10), \\
H_{j}=0,0,0,0,70,110,150,220,320,430,500, \\
700,700,700,700 \mathrm{~km} \quad(j=-3,-2, \ldots, 11) .
\end{gathered}
$$

Solid curves in Fig. 12 show fitted $\gamma_{V}(L, H)$. Coefficients of the spline functions are shown in Table 3 . By introducing
$\gamma_{V}(L, H)$, the RMS deviations are reduced as $0.57 \rightarrow 0.48$, $0.47 \rightarrow 0.42,0.48 \rightarrow 0.43,0.50 \rightarrow 0.44$, and $0.47 \rightarrow 0.39$ for Figs. 12(b)-(f), respectively. The RMS deviation for shallow earthquakes (Fig. 12(a)) is not reduced.

Figure 13 shows attenuation of $S$-wave $\left(\exp \left(-\int \frac{\pi f}{Q_{S}} d t\right)\right)$ calculated from the $Q_{S}$ model in Fig. 2 for a hypothetical set of hypocenters and observation stations. Frequency of the seismic waves, $f$, is assumed $1.5 \mathrm{~Hz}$. The hypothetical earthquakes are located at the top of the Pacific plate along the latitude line of $40^{\circ} \mathrm{N}$, along which the Pacific plate subducts to the depths deeper than $500 \mathrm{~km}$. The observation stations are distributed along $35^{\circ} \mathrm{N}$, where actual stations are densely distributed. Comparing Fig. 13 with Fig. 12, we see similar patterns of attenuation curves for the distance range of 100 $400 \mathrm{~km}$ and depth range of $200-400 \mathrm{~km}$. Although the pattern of attenuation variations may vary for different sets of plate and station locations, Fig. 13 clearly demonstrates the effect of inhomogeneous $Q$ structure. We conclude that the effect of inhomogeneous attenuation was effectively reduced by introducing $\gamma_{V}(L, H)$, in spite of two-dimensional modeling of $Q$ structure (see Fig. 12).

\section{Discussion}

The velocity-amplitude magnitudes of deep events depend on the assumed $Q$ structure. For a different $Q$ model, the magnitude value could be different.

For the $Q_{S}$ model of Fig. 2, $Q_{S}$ values of Flanagan and Wiens (1994) were modified based on the frequency dependence of $Q$ value reported by Choy and Cormier (1986). Some other researchers reported that $Q_{S}$ value increases with 


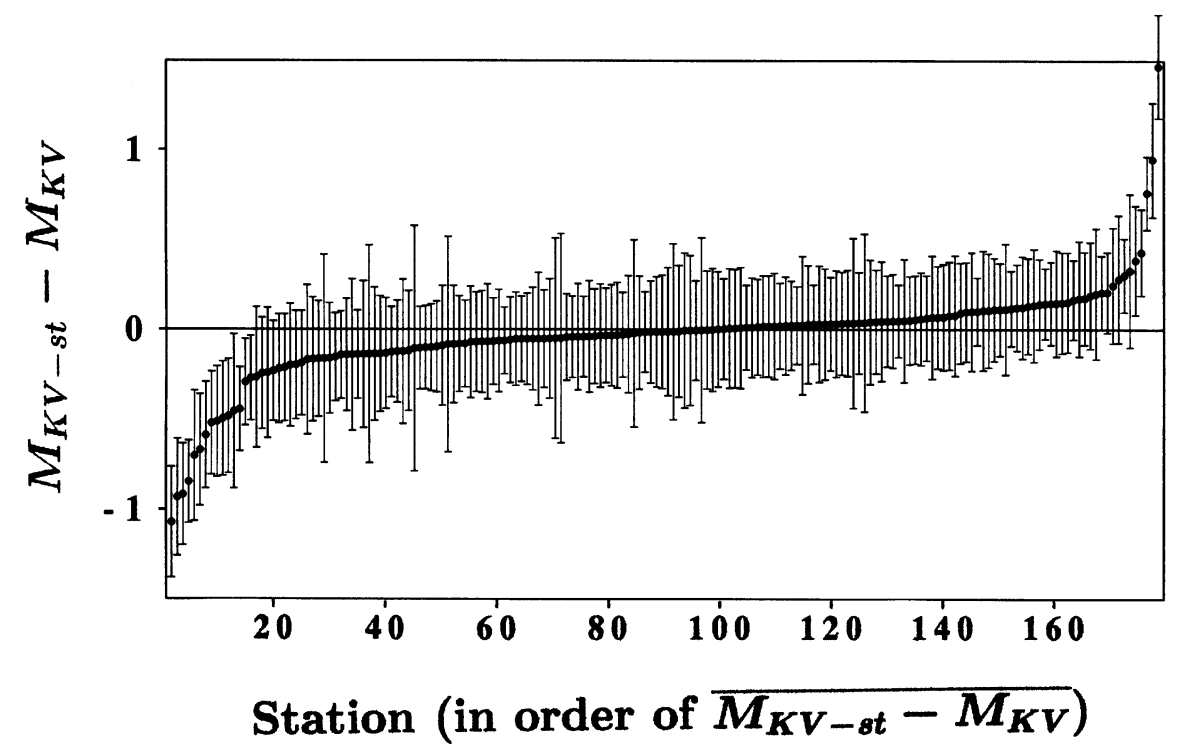

Fig. 17. Average differences between station magnitude, $M_{K V-s t}$, and earthquake magnitude, $M_{K V}$. The station magnitude is sorted on the horizontal axis.

the frequency of seismic waves (e.g., Taylor et al., 1986; Ordaz and Singh, 1992). In these reports, $Q_{S}$ at $0.1 \mathrm{~Hz}$ is two to several times smaller than that at $1.0 \mathrm{~Hz}$. In this study, earthquakes of magnitude 4-5 are mainly used for the estimation of attenuation function in deep regions. For those earthquakes, frequency range of $0.3-1.0 \mathrm{~Hz}$ was used to estimate seismic moments. The reported variations of the frequency dependence scatter up to a few times in the analyzed frequency band.

Sato and Fehler (1997) summarized reports on $Q_{P}^{-1} / Q_{S}^{-1}$ for the lithosphere. In many of the those estimates, $Q_{P}$ was smaller than $Q_{S}$ in the frequency range higher than $1 \mathrm{~Hz}$. For the frequency range lower than $0.3 \mathrm{~Hz}, Q_{P}$ was larger than $Q_{S}$ (e.g., Taylor et al., 1986; Anderson and Hart, 1978). In this study, $Q_{P}$ was assumed as $\frac{9}{4} Q_{S}$ after Anderson $e$ al . (1965). The ratio of $Q_{P} / Q_{S}$ we used might be too large. But, the reports referred to in Sato and Fehler (1997) are mostly concerned with the attenuation in the lithosphere, and there is no clear evidence of denying the prediction by Anderson et al. (1965) for the deep regions.

According to various reports, a few times of difference in $Q$ values from those in Fig. 2 might be possible to exist. Figure 14 shows how much $Q$ values affect synthetic records. Observed and synthetic records at MONO for an earthquake (July 21, 1997 7:21:14.2(JST), 32.243 ${ }^{\circ} \mathrm{N}, 137.747^{\circ} \mathrm{E}, H 424$ km, $M_{w} 3.6$; see Fig. 3), are shown in the top panels. In the lower panels, we show synthetic records for the $Q$ structure shown in Fig. 2 (bold solid curves), that with half $Q$ values of Fig. 2 (thin solid curves), and that with double $Q$ values of Fig. 2 (thin broken curves). Observed and synthetic records were processed with a Bessel band-pass filter (Katsumata, 1993 ) with a $0.8-1.4 \mathrm{~Hz}$ pass-band. Amplitudes of synthetic records differ significantly, depending on $Q$ values.

A broken curve in the top panel in Fig. 14 shows a synthetic record based on the moment-tensor solution estimated with the $Q$ model in Fig. 2. The trace of the moment tensor matrix was assumed to be zero in the estimation. Estimated scalar
Table 4. Estimated scalar moments of an earthquake, which occurred on July 21,1997 at a depth of $424 \mathrm{~km}$, for different $Q$ structures.

\begin{tabular}{lc}
\hline \multicolumn{1}{c}{$Q$ structure } & Estimated scalar moment \\
\hline This study (Fig. 2) & $3.4 \times 10^{15} \mathrm{Nm}\left(M_{w}=3.6\right)$ \\
Half of Fig. 2 & $7.3 \times 10^{15} \mathrm{Nm}\left(M_{w}=3.8\right)$ \\
Double of Fig. 2 & $2.0 \times 10^{15} \mathrm{Nm}\left(M_{w}=3.5\right)$ \\
$Q_{S}=10000$ & $0.8 \times 10^{15} \mathrm{Nm}\left(M_{w}=3.2\right)$ \\
\hline
\end{tabular}

Table 5. The slopes of regression lines in Fig. 15 and corrected values of the coefficient for $\log A_{V}, \alpha_{V}^{\prime}$. The kinds of moment catalogs are the same as those in Fig. 5.

\begin{tabular}{lr}
\hline Moment catalog & \multicolumn{1}{c}{ slope $\left(\alpha_{V}^{\prime}\right)$} \\
\hline This study & $0.019(1.15)$ \\
EIC & $-0.041(1.23)$ \\
FREESIA & $0.015(1.17)$ \\
ERI CMT & $0.208(0.97)$ \\
\hline
\end{tabular}

moments for different $Q$ structures are shown in Table 4 . Estimated seismic moments differ by a factor of about 2-3 for half or double $Q$ values in this case. This difference of scalar moment corresponds to a difference of $0.2-0.3$ in the magnitude unit.

In Eqs. (4) and (6), $\alpha_{V}$ was assumed to be $1 / 0.85$ (=1.18) following Watanabe (1971). Figure 15 shows relationships between the moment magnitude of various catalogs and the velocity-amplitude magnitude of the present study:

$$
M_{K V}=\alpha_{V} \log _{10} A_{V}+\beta_{V}(\Delta, H)+\gamma_{V}(L, H) .
$$

The slopes of regression lines in the magnitude ranges of $M_{w}<4.7(H \leq 50 \mathrm{~km})$ and $M_{w}<5.3(H>50 \mathrm{~km})$ 
are shown in Table 5. Corrected values of the coefficient, $\alpha_{V}^{\prime}=\alpha_{V} /(1+a)$, are also shown in the table, where $\alpha_{V}$ is the initially assumed value $(=1 / 0.85)$ and $a$ is the slope of the regression line. The corrected values, $\alpha_{V}^{\prime}$, bound the value of $1 / 0.85$ (= 1.18) obtained by Watanabe, which is therefore considered a good estimation of the coefficient for moment magnitude, as well as for Tsuboi's magnitude.

In Fig. 1, we plotted the magnitude-frequency relationship for the velocity-amplitude magnitude of this study (large solid circles), and a combination of the displacement-amplitude magnitude (Tsuboi, 1954), $M_{T}$, and $M_{K V}$ (small solid circles). For the combination, displacement-amplitude magnitude is used when displacement-amplitude magnitude is available. For $M_{K V}$, saturation is recognized in the magnitude range of $M_{K V}>5.8$, which is considered due to the frequency response of short-period instruments. For the combination of $M_{T}$ and $M_{K V}$, the bend around magnitude 5.0 that appeared for $M_{J M A}$ is not seen. This indicates validity of the magnitude determination method developed in this study.

The velocity-amplitude magnitude of this study, $M_{K V}$, is compared with some other magnitudes in Fig. 16. Figure 16(a) shows comparison between $M_{K V}$ and the displacement-amplitude magnitude, $M_{K D}$, defined by Katsumata (1999), which was adjusted to the moment magnitude of Dziewonski et al. (1981). The average of $M_{K V}-M_{K D}$ over all depth ranges is -0.09 for magnitude ranges of $M_{K D} \leq 4.7$ $(H \leq 50 \mathrm{~km})$ and $M_{K D} \leq 5.3(H>50 \mathrm{~km})$. Some magnitude dependences are recognized in $M_{K V}-M_{K D}$. For six earthquakes of $M_{K D} \leq 4.7(H \leq 50 \mathrm{~km})$ and $M_{K D} \leq 5.3(H>50 \mathrm{~km})$, the deviation is relatively large; $\left|M_{K V}-M_{K D}\right|>1.0$. Since more than several amplitude data were used for both displacement and velocity for these earthquakes, the differences should not be attributed to irregular data of small number. It is considered that the excitation of high frequency $(f>1 \mathrm{~Hz})$ was weak for those earthquakes.

Figure 16(b) shows comparison between the body-wave magnitude, $m_{b}$, of USGS and magnitude of this study, $M_{K V}$. Magnitude dependence of $m_{b}-M_{K V}$ is seen; $m_{b}$ is smaller than $M_{K V}$ in magnitude range of $M_{K V}>5$, and larger in magnitude range of $M_{K V}<4.5$ on average. However, strong dependence on the depth is not seen.

Figure 16(c) shows comparison between $M_{K V}$ and the current JMA magnitude, $M_{J M A}$. Due to the difference in the coefficient for $\log _{10} A_{V}$, the difference between the two magnitudes reaches 0.8 at $M_{K V}=2$ for shallow earthquakes $(H \leq 100 \mathrm{~km})$.

Site condition affects observed amplitude, and the magnitude computed for a single station, $M_{K V-s t}$, may vary from station to station. Figure 17 presents the difference between station magnitudes, $M_{K V-s t}$, and earthquake magnitude, $M_{K V}$. In the figure, small solid circle and attached bar indicate the average and standard deviation, respectively. The station number on the horizontal axis is sorted in the order of average residual. At $88 \%$ of stations, the deviation of station magnitude is less than 0.3 in magnitude unit, which corresponds to halving or doubling amplitude. When $12 \%$ of stations with large deviations are excluded, the deviation due to the site effect should be reduced to less than 0.3 in magnitude without individual station corrections.

\section{Conclusion}

We proposed a new method to determine earthquake magnitude from velocity-amplitude data obtained with shortperiod seismometers of a regional network. The velocityamplitude magnitude, $M_{K V}$, is defined by Eq. (7), where $A_{V}$ is the half of the peak-to-peak maximum velocity amplitude $(\mathrm{m} / \mathrm{s})$. Based on the observation data of the Japan Meteorological Agency network, we obtained best-fit values for the two parameters, $\beta_{V}$ and $\gamma_{V}$, by fixing $\alpha_{V}$ at 1.18. The attenuation function $\beta_{V}$ was estimated as was shown in Fig. 9, by using moment magnitudes that were newly calculated with an inhomogeneous $Q$ structure model. The effect of inhomogeneous $Q$ structure is further corrected by $\gamma_{V}$, which is a function of the epicentral distance from the trench axis to an observation station and focal depth (see Table 3). The velocity-amplitude magnitude, $M_{K V}$, is satisfactorily scaled to the moment magnitude, and provides a stable magnitude estimate for any focal depths seamlessly.

Acknowledgments. The author is grateful to Prof. M. Ohtake at Tohoku University and an anonymous reviewer for their helpful comments and suggestions.

\section{References}

Aki, K., Scaling law of seismic spectrum, J. Geophys. Res., 72, 1217-1231, 1967.

Anderson, D. L. and R. S. Hart, $Q$ of the Earth, J. Geophys. Res., 83, 5869-5882, 1978

Anderson, D. L., A. Ben-Menahem, and C. B. Archambeau, Attenuation of seismic energy in the upper mantle, J. Geophys. Res., 70, 1441-1448, 1965.

Bowman, J. R., Body wave attenuation in the Tonga subduction zone, $J$. Geophys. Res., 93, 2125-2139, 1988.

Campbell, K. W., Empirical near-source attenuation relationships for horizontal and vertical components of peak ground acceleration, peak ground velocity, and pseudo-absolute acceleration response spectra, Seism. Res. Lett., 68, 154-179, 1997.

Choy, G. L. and V. F. Cormier, Direct measurement of the mantle attenuation operator from broadband $\mathrm{P}$ and $\mathrm{S}$ waveforms, J. Geophys. Res., 91, 7326$7342,1986$.

Duda, S. J., Travel times and body wave magnitude, $P A G E O P H, 87,13-37$, 1971.

Dziewonski, A. M., T.-A. Chou, and J. H. Woodhouse, Determination of earthquake source parameters form waveform data for studies of global and regional seismicity, J. Geophys. Res., 86, 2825-2852, 1981.

Flanagan, M. P. and D. A. Wiens, Radial upper mantle attenuation structure of inactive back arc basins from differential shear wave measurements, J. Geophys. Res., 99, 15469-15485, 1994.

Fukuyama, E., M. Ishida, D. S. Dreger, and H. Kawai, Automated seismic moment tensor determination by using on-line broadband seismic waveforms, Zisin, II, 51, 149-156, 1998 (in Japanese with English abstract).

Hashida, T., Three-dimensional seismic attenuation structure beneath the Japanese islands and its tectonic and thermal implications, Tectonophys., 159, 163-180, 1989.

Ichida, K. and F. Yoshimoto, Spline Functions and Their Applications, 220 pp., Kyoiku-shuppan, Tokyo, 1979 (in Japanese).

Japan Meteorological Agency, The Seismological Bulletin of the Japan Meteorological Agency for January 1995, 106 pp., Tokyo, 1997.

Joyner, W. B. and D. M. Boore, Peak horizontal acceleration and velocity from strong motion records including records from the 1979 Imperial Valley, California, Earthquake, Bull. Seism. Soc. Am., 71, 2011-2038, 1981 .

Kakishita, T., I. Sasakawa, M. Kobayashi, A. Nagai, and N. Hamada, An examination of JMA formulas for determining magnitude using data obtained by the JMA-87 type electromagnetic strong motion seismograph, Zisin, II, 45, 263-277, 1992 (in Japanese with English abstract).

Kanamori, H., The energy release in great earthquakes, J. Geophys. Res., 82, 2981-2987, 1977. 
Kanbayashi, Y. and M. Ichikawa, A method for determining magnitude of shallow earthquakes occurring in and near Japan, Quart. J. Seism., 41, 57-61, 1977 (in Japanese with English abstract).

Katsumata, A., Automatic designing of Bessel digital filters, Quart. J. Seism., 56, 17-34, 1993 (in Japanese).

Katsumata, A., Comparison of magnitudes estimated by the Japan Meteorological Agency with moment magnitudes for intermediate and deep earthquakes, Bull. Seism. Soc. Am., 86, 832-842, 1996.

Katsumata, A., Attenuation function of displacement amplitude for magnitude calculation, Pap. Meteorol. Geophys., 50, 1-14, 1999.

Katsumata, A., Seismic moment estimation of small earthquakes by waveform fitting, Pap. Meteorol. Geophys., 51, 1-15, 2000.

Kawakatsu, H., Automated near-realtime CMT inversion, Geophys. Res. Lett., 22, 2569-2572, 1995.

Kikuchi, M. and M. Ishida, Source retrieval for deep local earthquakes with broadband records, Bull. Seism. Soc. Am., 83, 1855-1870, 1993.

Molas, G. L. and F. Yamazaki, Attenuation of earthquake ground motion in Japan including deep focus events, Bull. Seism. Soc. Am., 85, 1343-1358, 1995.

Ordaz, M. and S. K. Singh, Source spectra and spectral attenuation of seismic waves from Mexican earthquakes, and evidence of amplification in the hill zone of Mexico city, Bull. Seism. Soc. Am., 82, 24-43, 1992.

Sato, H. and M. C. Fehler, Seismic Wave Propagation and Scattering in the Heterogeneous Earth, 308 pp., Springer-Verlag New York, Inc., New York, 1997.

Solov'yeva, O. N., Magnitude determination of deep-focus earthquakes, Izv., Acad. Sci. USSR, Phys. Solid Earth, 14, 16-21, 1978.
Takeo, M., Near-field synthetic seismograms taking into account the effects of anelasticity - the effects of anelastic attenuation on seismograms caused by sedimentary layer-, Pap. Meteorol. Geophys., 36, 245-257, 1985 (in Japanese with English abstract).

Takeuchi, H., Magnitude determination of small shallow earthquakes with JMA electromagnetic seismograph Model 76, Quart. J. Seism., 47, 112116, 1983 (in Japanese with English abstract).

Taylor, S. R., B. P. Bonner, and G. Zandt, Attenuation and scattering of broadband $\mathrm{P}$ and $\mathrm{S}$ waves across North America, J. Geophys. Res., 91, 7309-7325, 1986.

Tsuboi, C., Determination of the Gutenberg-Richter's magnitude of earthquakes occurring in and near Japan, Zisin, II, 7, 185-193, 1954 (in Japanese with English abstract).

Umino, N. and A. Hasegawa, Three-dimensional $Q_{S}$ structure in the northeastern Japan Arc, Zisin, II, 37, 217-228, 1984 (in Japanese with English abstract).

Veith, K. F. and G. E. Clawson, Magnitude from short-period P-wave data, Bull. Seism. Soc. Am., 62, 435-452, 1972.

Watanabe, H., Determination of earthquake magnitude at regional distance in and near Japan, Zisin, II, 24, 189-200, 1971 (in Japanese with English abstract).

Yoshioka, K. and Y. Iio, Re-examination of magnitude's formula for records of velocity seismograph with natural frequency of $1 \mathrm{~Hz}$, Zisin, II, 41, 437-441, 1988 (in Japanese).

A. Katsumata (e-mail: akatsuma@typhoon.mc-jma.ac.jp) 